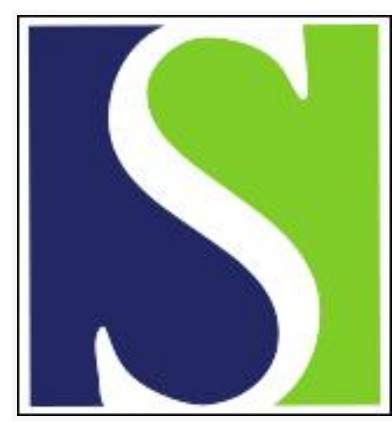

Scand J Work Environ Health 1991;17(6):380-385

https://doi.org/10.5271/sjweh.1690

Issue date: Dec 1991

Job strain and ambulatory blood pressure profiles.

by Theorell T, de Faire U, Johnson J, Hall E, Perski A, Stewart W

Affiliation: National Institute of Psychosocial Factors and Health, Stockholm, Sweden.

The following article refers to this text: 2014;40(2):109-132

This article in PubMed: www.ncbi.nlm.nih.gov/pubmed/1788530

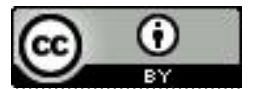




\title{
Job strain and ambulatory blood pressure profiles
}

\author{
by Tores Theorell, MD, ${ }^{1,2}$ Ulf de Faire, MD, ${ }^{3}$ Jeffrey Johnson, $\mathrm{PhD},{ }^{4}$ Ellen Hall, DMSc, ${ }^{4}$ \\ Aleksander Perski, PhD, ${ }^{1}$ Walter Stewart, $\mathrm{PhD}^{4}$
}

\begin{abstract}
THEORELL T, de FAIRE U, JOHNSON J, HALL E, PERSKI A, STEWART W. Job strain and ambulatory blood pressure profiles. Scand $J$ Work Environ Health 1991;17:380-5. Occupational characteristics were used to study the role of job stress in the pathogenesis of hypertension. Ambulatory $24-\mathrm{h}$ recordings of blood pressure were made for 161 men with borderline hypertension. From the occupational classification system scores for psychological demands, control, support, physical demands, and occupational hazards were obtained. The results indicated that the ratio between psychological demands and control (strain) was significantly associated with diastolic (but not systolic) blood pressure at night and during work. The association between job strain and diastolic blood pressure at night and during work was greatly strengthened when the subjects with occupations classified as physically demanding were excluded from the analysis. The conclusion was reached that a measure of job strain derived from the occupational classification is useful in predicting variations in diastolic blood pressure levels during sleep and work for men with borderline hypertension.
\end{abstract}

Key terms: blood pressure levels, borderline hypertension, continuous blood pressure monitoring, psychological job strain.

Recently several studies have shown that an association exists between exposure to job strain [defined according to Karasek as the combined effect of high psychological demands and low decision latitude (1)] and the risk of coronary heart disease $(2-10)$. It is not known, however, whether this association is due mainly to the effect of job strain on known biomedical risk factors or to other, more direct mechanisms. Some of the studies that have tested this question indicate that part of the influence could be outside that of the accepted risk factors $(8-10)$. Others have shown that there may be a relationship between job strain and smoking $(11,12)$, and some have indicated a relationship between job strain and blood pressure or blood pressure variations $(13-15)$. There are also studies which indicate an absence of relationship between job strain and blood pressure $(16,17)$.

The diverging results between the studies on blood pressure may be due to differences in methodology and samples. Part of the difficulty is due to the fact that subjects who are vulnerable to the development of hypertension may underreport problems at work (18). Accordingly it is important to construct questions that

1 National Institute of Psychosocial Factors and Health, Stockholm, Sweden.

2 Department of Occupational Medicine, Karolinska Hospital, Stockholm, Sweden.

3 Division of Cardiovascular Medicine, Department of Medicine, Karolinska Hospital, Stockholm, Sweden.

${ }_{4}$ School of Public Health, Johns Hopkins University, Baltimore, Maryland, United States.

Reprint requests to: Professor T Theorell, National Institute of Psychosocial Factors and Health, PO Box 602210, S-104 01 Stockholm, Sweden. avoid such bias. Another possibility, utilized in the present study, is to rely on an objective classification system for occupations, one which assesses the psychosocial work environment without reference to individual perception. In this way subjective distortion is avoided. However, the measures that are used are necessarily imprecise because they rely on the assumption that all subjects working in a given occupation have the same psychosocial condition.

\section{Subjects and methods}

\section{Subjects}

The subjects of the investigation were recruited on the basis of a screening study of all men aged $35-55$ years and living in a community north of Stockholm. The area is partly rural, partly suburban. There were 2900 men who participated in the first screening study.

Blood pressure was measured in the supine position after 5 min of rest. After the initial screening the individuals were grouped according to diastolic blood pressure into three groups, namely, normotensives ( $<85 \mathrm{~mm} \mathrm{Hg} ;<11.3 \mathrm{kPa}$ ), borderline $(85-94 \mathrm{~mm}$ $\mathrm{Hg} ; 11.3-12.5 \mathrm{kPa}$ ), and hypertensives $(\geq 95 \mathrm{~mm} \mathrm{Hg}$; $\geq 12.6 \mathrm{kPa}$ ). There were 740 subjects in the borderline group. These individuals went through two more tests. Those who had participated in the latter two $(\mathrm{N}=193)$ and who were still found to have borderline hypertension according to the same criteria remained eligible for the present study. Of these 161 were willing to participate. The blood pressure of these subjects was monitored with a Del Mar Avionics noninvasive blood pressure system (PIII). Ambulatory blood pressure measurements were made every $7.5 \mathrm{~min}$ during 
an ordinary workday and throughout $24 \mathrm{~h}$. Those who participated in the measurements had had a night of ordinary sleep before the recording started, and they worked during the daytime. The subjects were told not to restrict their usual activities during the registration period. Before the registration was started, automatic readings were cross-checked against manually auscultated blood pressures measured through the same cuff via a Y-tube connected to a mercury sphygmomanometer. The monitoring was not started unless good agreement was obtained between two measurements (disagreement $<5 \mathrm{~mm} \mathrm{Hg} ;<0.7 \mathrm{kPa}$ ) for both the systolic and the diastolic blood pressure.

Blood pressure averages were calculated for every hour of the 24-h measurement period from the first four measurements. From these averages the mean systolic and diastolic blood pressures were calculated for the night $(0100-0700)$, workhours $(0800-1700)$, and finally for leisure time $(1800-2400)$.

\section{Job strain and occupational characteristics}

The job conditions were recorded by means of questions regarding job title. The three-digit Nordic classification system for occupations was used. In order to rate the psychosocial and physical demands of the occupations, the classification system of Johnson et al (19) was used. This system is based upon 12084 randomly selected employed Swedish citizens between the ages of 25 and 74 years who were interviewed in 1977 (half of the sample) and 1979 (other half of the sample) about their work conditions. After psychometric modeling three psychosocial work dimensions, namely, psychological demands (Is your job hectic? and Is your job psychologically demanding?), control (12 questions about influence over a number of factors at work, such as planning, setting of work pace, planning of vacations, selection of supervisor, flexibility of workhours, variation in content and procedures, and possibility to learn new things and experience personal fulfillment), and support (four questions regarding possibility to interact with co-workers during breaks and during work and habit of seeing colleagues outside work) were constructed. Two physical work dimensions were also constructed, namely, physical job demands (five questions about unsuitable work postures, heavy lifting, perspiration, dirtiness, and accident risk) and hazardous work (seven questions about noise, shaking and vibration, cold, draft, inadequate ventilation, lighting and gas, and mist or smoke). All of the scales were standardized in such a way that the scores ranged from 0 to 10 . Of importance to our study is that tables for the different occupations have been presented with different means for the men and women and for the subjects below and above the age of 45 years. According to previously formulated practice (13), job strain was computed as the ratio between the psychological demands and control.

\section{Statistical methods}

The distributions of the psychosocial work characteristics were close to normal with the exceptions of physical demand and support. The physical demand scale showed a bimodal distribution. Half of the sample reported no or hardly any physical demand (below score 2.2), whereas the remaining subjects reported a variable amount of physical demand, the normal distribution ranging from 2.3 to 10 . The support scale was slightly skewed to the right - a disproportionate number of subjects were working in occupations with good support. Because of the importance of physical demand and the bimodal distribution of this variable two statistics were used.

Initially, age and each one of the four work dimensions (job strain, support, physical demands, and hazardous work) were used as explanatory variables in a stepwise multiple regression analysis using each one of the six blood pressure variables systolic blood pressure at night, systolic blood pressure at work, systolic blood pressure during leisure, diastolic blood pressure at night, diastolic blood pressure at work, and diastolic blood pressure during leisure as dependent variables. Thereafter, job strain was categorized into upper quartile, lower quartile, and middle groups, and physical demands were classified into two groups $(0-2.2$ and $2.3-10$ ). Two-way analyses of variance were performed with the job strain and physical demand categories as explanatory variables and each one of the six blood pressure variables as dependent variables.

\section{Results}

The results of the stepwise multiple regression analyses are presented in table 1 . We observed that physical work demands were significantly associated with systolic blood pressure levels at night. None of the other variables were significantly associated with systolic blood pressure at work, at night, or during leisure. None of the variables were statistically associated with systolic blood pressure during work or leisure. For diastolic blood pressure the situation was different. Both physical demands and job strain were associated with diastolic blood pressure levels at night, and job strain was the only work variable that was statistically associated with diastolic blood pressure during work. Hazardous work was associated with diastolic blood pressure during leisure.

The results of the two-way analyses of variance for systolic blood pressure (table 2) showed that there was a statistically significant effect of physical demands both at night and during work. During leisure, on the other hand, physical work demands were not associated with systolic blood pressure. A statistically significant interaction between physical demands and job strain in the effect on systolic blood pressure was observed for the night, work, and leisure values. For diastolic blood pressure (table 3 ) there was a statisti- 
Table 1. Results of the multiple regression analyses using age, job strain, physical demands, and hazardous work as the explanatory variables and times of $0100-0700,0800-1700$, and $1800-2400$ as the dependent variables. Only significant variables ( $F$ to enter $4.000, F$ to remove 3.996 ) are presented.

\begin{tabular}{|c|c|c|c|c|c|}
\hline Blood pressure variable & Step & Explanatory variable & $F$ & $\begin{array}{c}\text { Adjusted } \\
\mathrm{R}^{2}\end{array}$ & $\begin{array}{l}\text { Total } \\
\text { degrees } \\
\text { of } \\
\text { freedom }\end{array}$ \\
\hline \multicolumn{6}{|l|}{ Systolic } \\
\hline $\begin{array}{l}\text { Between the hours of } 0100 \text { and } 0700 \\
\text { Between the hours of } 0800 \text { and } 1700 \\
\text { Between the hours of } 1800 \text { and } 2400\end{array}$ & $\begin{array}{l}1 \\
\cdot \\
\cdot\end{array}$ & $\begin{array}{l}\text { Physical demands } \\
\text { No variable significantly associated } \\
\text { No variable significantly associated }\end{array}$ & $\begin{array}{c}4.68 \\
\cdot \\
\cdot\end{array}$ & 0.026 & $\begin{array}{c}140 \\
. \\
.\end{array}$ \\
\hline \multicolumn{6}{|l|}{ Diastolic } \\
\hline $\begin{array}{l}\text { Between the hours of } 0100 \text { and } 0700 \\
\text { Between the hours of } 0800 \text { and } 1700 \\
\text { Between the hours of } 1800 \text { and } 2400\end{array}$ & $\begin{array}{l}1 \\
2 \\
1 \\
1\end{array}$ & $\begin{array}{l}\text { Physical demands } \\
\text { Job strain } \\
\text { Job strain } \\
\text { Hazardous work }\end{array}$ & $\begin{array}{l}7.83 \\
5.81 \\
4.27 \\
5.10\end{array}$ & $\begin{array}{l}0.039 \\
0.026 \\
0.022 \\
0.028\end{array}$ & $\begin{array}{l}139 \\
139 \\
145 \\
145\end{array}$ \\
\hline
\end{tabular}

Table 2. Results of the two-way analysis of variance with the systolic blood pressure at the times of $0100-0700,0800-1700$, and $1800-2400$ as the dependent variables and the categories of physical demand and job strain as the explaining variables.

\begin{tabular}{|c|c|c|c|c|}
\hline & \multicolumn{4}{|c|}{ Physical demand } \\
\hline & \multicolumn{2}{|c|}{ Low } & \multicolumn{2}{|c|}{ High } \\
\hline & Number & Mean & Number & Mean \\
\hline \multicolumn{5}{|c|}{$\begin{array}{l}\text { Between the hours of } 0100 \text { and } 0700 \\
\text { Job strain }\end{array}$} \\
\hline $\begin{array}{l}\text { Low } \\
\text { Medium } \\
\text { High }\end{array}$ & $\begin{array}{l}11 \\
50 \\
19\end{array}$ & $\begin{array}{l}108.1 \\
107.4 \\
110.2\end{array}$ & $\begin{array}{l}28 \\
10 \\
24\end{array}$ & $\begin{array}{l}109.2 \\
123.1 \\
111.6\end{array}$ \\
\hline $\begin{array}{l}\text { Main effect strain } \\
\text { Main effect physical demand } \\
\text { Interaction }\end{array}$ & $\begin{array}{l}F=2.40 \\
F=6.27 \\
F=3.90\end{array}$ & $\begin{array}{l}P=0.095 \\
P=0.013 \\
P=0.023\end{array}$ & & \\
\hline \multicolumn{5}{|c|}{$\begin{array}{l}\text { Between the hours of } 0800 \text { and } 1700 \\
\text { Job strain }\end{array}$} \\
\hline $\begin{array}{l}\text { Low } \\
\text { Medium } \\
\text { High }\end{array}$ & $\begin{array}{l}11 \\
54 \\
20\end{array}$ & $\begin{array}{l}131.5 \\
129.9 \\
134.8\end{array}$ & $\begin{array}{r}28 \\
9 \\
25\end{array}$ & $\begin{array}{l}132.9 \\
145.4 \\
132.8\end{array}$ \\
\hline $\begin{array}{l}\text { Main effect strain } \\
\text { Main effect physical demand } \\
\text { Interaction }\end{array}$ & $\begin{array}{l}F=1.88 \\
F=4.66 \\
F=5.67\end{array}$ & $\begin{array}{l}P=0.157 \\
P=0.033 \\
P=0.004\end{array}$ & & \\
\hline \multicolumn{5}{|c|}{$\begin{array}{l}\text { Between the hours of } 1800 \text { and } 2400 \\
\text { Job strain }\end{array}$} \\
\hline $\begin{array}{l}\text { Low } \\
\text { Medium } \\
\text { High }\end{array}$ & $\begin{array}{l}11 \\
54 \\
20\end{array}$ & $\begin{array}{l}129.1 \\
125.2 \\
131.7\end{array}$ & $\begin{array}{r}28 \\
9 \\
25\end{array}$ & $\begin{array}{l}127.3 \\
138.6 \\
128.3\end{array}$ \\
\hline $\begin{array}{l}\text { Main effect strain } \\
\text { Main effect physical demand } \\
\text { Interaction }\end{array}$ & $\begin{array}{l}F=0.82 \\
F=1.47 \\
F=5.55\end{array}$ & $\begin{array}{l}P=0.441 \\
P=0.228 \\
P=0.005\end{array}$ & & \\
\hline
\end{tabular}

cally significant main effect for job strain at night, during work, and during leisure, and physical demands also showed a main effect for diastolic blood pressure at night and during leisure. Statistically significant interactions between physical demands and job strain in the effect on diastolic blood pressure were observed for the night, work, and leisure values. Figure 1 shows the mean diastolic blood pressure levels for each of the $24 \mathrm{~h}$ in the sample of subjects who were working in occupations without heavy physical demands. The sample has been divided according to the same categorization as in the two-way analyses of variance into low, medium, and high job strain. Only subjects with four valid initial measurements during the hour have been included. The numbers of subjects varied between 5 and 11 in the low strain, between 25 and 52 in the medium strain, and between 11 and 20 in the high strain groups. One-way analyses of variance showed that there were statistically significant differences between the three groups at $2,3,4,5,6,9,10,12,14$, 17,18 , and $23 \mathrm{~h}$. All of the differences were in the predicted direction - low strain lower than medium strain and medium strain lower than high strain.

Data from self-report protocols showed that 745 of the $896(83 \%)$ reports made for the hours in the time interval $0100-0700$ indicated that the subject had been sleeping. Reports for 500 of the $1273(39 \%)$ hours during the time interval 0800 to 1700 indicated that 
Table 3. Results of the two-way analysis of variance with the diastolic blood pressure at the times of $0100-0700,0800-1700$ and $1800-2400$ as the dependent variables and the categories of physical demand and job strain as the explaining variables.

\begin{tabular}{|c|c|c|c|}
\hline \multicolumn{4}{|c|}{ Physical demand } \\
\hline \multicolumn{2}{|c|}{ Low } & \multicolumn{2}{|c|}{ High } \\
\hline Number & Mean & Number & Mean \\
\hline
\end{tabular}

Between the hours of 0100 and 0700

Job strain

$$
\begin{aligned}
& \text { Low } \\
& \text { Medium } \\
& \text { High }
\end{aligned}
$$

Main effect strain

Main effect physical demand

Interaction

Between the hours of 0800 and 1700

Job strain

$$
\begin{aligned}
& \text { Low } \\
& \text { Medium } \\
& \text { High }
\end{aligned}
$$

Main effect strain

Main effect physical demand

Interaction

$\begin{array}{lc}11 & 63.9 \\ 50 & 71.3 \\ 19 & 74.1 \\ \mathrm{~F}=6.45 & \mathrm{P}=0.002 \\ \mathrm{~F}=6.51 & \mathrm{P}=0.012 \\ \mathrm{~F}=4.13 & \mathrm{P}=0.018\end{array}$

Between the hours of 1800 and 2400

Job strain

$$
\begin{aligned}
& \text { Low } \\
& \text { Medium } \\
& \text { High }
\end{aligned}
$$

Main effect strain

Main effect physical demand

Interaction

$\begin{array}{lc}11 & 78.4 \\ 54 & 85.8 \\ 20 & 90.3 \\ F=6.06 & P=0.003 \\ F=1.96 & P=0.164 \\ F=7.17 & P=0.001\end{array}$

$\begin{array}{rr}28 & 71.7 \\ 9 & 76.9 \\ 24 & 72.3\end{array}$

the subject had been working, and for an additional 247 observations ( $19 \%$ ) there had been both work and leisure activities. During the interval 1800 to 2400 notations were available for $925 \mathrm{~h}$. Forty (4\%) of them indicated sleep, $663(72 \%)$ leisure, and $109(12 \%)$ work, whereas in $49(5 \%) \mathrm{h}$ there had been both work and leisure activities. Thus in the analyses of variance the interval $0100-0700$ was clearly characterized by sleep, whereas for the two other intervals there had been both leisure and work activities although the $0800-1700$ interval was more work-oriented than the 1800-2400 time interval.

\section{Discussion}

The technique of making inferences regarding job characteristics has both advantages and disadvantages. One advantage is that individually distorted descriptions can be avoided which may be of particular importance in the case of blood pressure regulation since subjects with borderline hypertension have been reported to underreport problems both at work and in their general life situation (18). One disadvantage is that worksites within one occupation may of course differ dramatically with regard to psychosocial job characteristics. Accordingly there is a risk of misclassification which may lead to an underestimation of the true association.

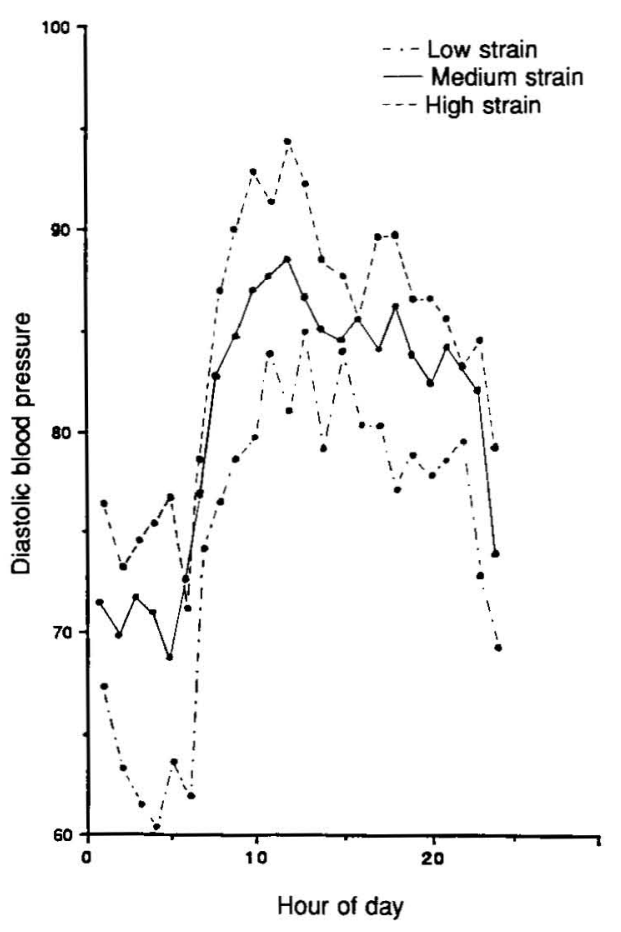

Figure 1. Mean diastolic blood pressure for each of the $24 \mathrm{~h}$ in the sample of subjects who were working in occupations without heavy physical demands. 
The sample studied was not necessarily representative of the general population of working Swedish men in greater Stockholm since they had gone through screening procedures which established that they all had borderline hypertension [diastolic blood pressure at rest $85-94 \mathrm{~mm} \mathrm{Hg}(11.3-12.5 \mathrm{kPa})$ on three occasions]. Thus they should be regarded as a population of men with borderline asymptomatic hypertension. In other words they all react more vigorously with blood pressure elevation to a number of stressors, both physical and psychosocial.

The analyses indicated that physical demands, as expected, are of importance to both systolic and diastolic blood pressure levels during the daily round of life. Job strain is also important, but only to diastolic blood pressure and only at night and during work, not during leisure. It is of interest that during work physical demands are not statistically associated with diastolic and only marginally associated with systolic blood pressure. One reason for this finding may be the wellknown fact that physical demands can introduce an artifact in $24-\mathrm{h}$ measurements. This possibility is due to spurious elevations of recorded blood pressures when arm muscles are contracted. Support for this interpretation is derived from the fact that in the analyses of variance the effect of job strain was very clear among the subjects in occupations without physical demands but nonexisting among those with physically strenuous occupations.

The observation that there is an association between job strain and diastolic blood pressure is in accordance with a recent study published by Schnall et al (14). It should be mentioned that psychological demands and control, used as separate variables in the multiple regression analysis, had no predictive value. This finding lends support to the Karasek theory, which states that it is the interaction between psychological demands and lack of control that is crucial.

The effects that we observed were small. This result could be due to the misclassification problem that arises when an inference system is used. However, another interpretation is that the muscle contraction artifact could cause a weakening of the association. This possibility is supported by the fact that, when the stepwise multiple regression with diastolic blood pressure during sleep and workhours as dependent variables was performed only with the subjects in occupations without physical demands, the adjusted explained variance for job strain was 10 and $12 \%$, respectively. (In this analysis adjustment was made for body mass as well.) This level is of the same size as the effect of the sympathoadrenal system on blood pressure levels (20). But it is also likely that physical demands may cause blood pressure elevations.

Only one previously published study (13) has explored the association between job strain measured by means of an occupational classification system and blood pressure regulation. It was an epidemiologic study of 28-year-old men. Among those who had had high blood pressure 10 years earlier, a significant association between systolic blood pressure during work and job strain was observed, but no association was seen for periods outside work or at rest. Among those who had had normal blood pressure at the age of 18 years, no significant association was observed. The present results differ from the previous ones in two ways. In the present study job strain was associated with blood pressure levels throughout $24 \mathrm{~h}$. Secondly, it was diastolic, not systolic, blood pressure that showed the strongest relationship. One explanation of the diverging results may be the age factor - the previous study was on young men and the present one involved middle-aged men. In middle-aged men who have repeatedly experienced an excessive elevation of blood pressure during workhours for many years sustained hypertension may have arisen - the most consistent differences were found during sleep.

Subjects in the high blood pressure group were found in the low job strain area. This result may indicate that in this cross-sectional study we were also facing the problem of selection - subjects with high blood pressure levels may have been selected into jobs with low levels of job strain. This phenomenon would, of course, attenuate the observed association.

In conclusion, the study indicates that there is an association between job strain measured by means of an occupational inference system and diastolic blood pressure. This association is not only seen for workhours, but also for sleep, particularly after subjects in occupations with heavy physical demands have been excluded. The mechanism behind this association is unknown.

\section{References}

1. Karasek RA. Job demands, job decision latitude, and mental strain: implications for job redesign. Adm Sci Q 1979;24:285-307.

2. Karasek RA, Baker D, Marxer F, Ahlbom A, Theorell $T$. Job decision latitude, job demands, and cardiovascular disease: a prospective study of Swedish men. Am J Public Health 1981;71:694-705.

3. Alfredsson L, Karasek R, Theorell T. Myocardial infarction risk and psychosocial environment: an analysis of the male Swedish working force. Soc Sci Med 1982;3:463-7.

4. Alfredsson L, Spetz C-L, Theorell T. Type of occupation and near-future hospitalization for myocardial infarction and some other diagnoses. Int $\mathrm{J}$ Epidemiol $1985 ; 14: 378-88$.

5. La Croix AZ. Occupational exposure to high demand/ low control work and coronary heart disease incidence in the Framingham cohort [Doctoral dissertation]. Chapel Hill, NC: Department of Epidemiology, University of North Carolina, 1984.

6. Hahn M. Job strain and cardiovascular disease: a tenyear prospective study. Am J Epidemiol 1985;122: $532-40$.

7. Johnson JV, Hall EM. Job strain, workplace social support and cardiovascular disease: a cross-sectional study of a random sample of the Swedish working population. Am J Public Health 1988;78:1336-42. 
8. Karasek RA, Theorell T, Schwartz J, Schnall P, Pieper $C$, Michela J. Job characteristics in relation to the prevalence of myocardial infarction in the US Health Examination Survey (HES) and the Health and Nutrition Examination Survey (HANES). Am J Public Health 1989;78:910-8.

9. Theorell T, Hamsten A, de Faire U, Orth-Gomer K, Perski A. Psychosocial work conditions before myocardial infarction in young men. Int $\mathrm{J}$ Cardiol 1987; $15: 33-46$.

10. Theorell T, Perski A, Orth-Gomer K, Hamsten A, de Faire U. The effects of the strain of returning to work on the risk of cardiac death after a first myocardial infarction before the age of 45 . Int J Cardiol 1991; 30:61-7.

11. Pieper C, La Croix AZ, Karasek RA. Job strain and cardiovascular risk factors for male workers in the US HANES I and HANES II, Western Collaborative Group Study, and Exercise Heart Study. Am J Epidemiol 1989; 129:483-94.

12. Green K. Job characteristics and health-related behaviors among chemical plant workers [Doctoral dissertation]. Baltimore, MD: Johns Hopkins University, 1988.

13. Theorell T, Perski A, Åkerstedt T, et al. Changes in job strain in relation to changes in physiological states: a longitudinal study. Scand J Work Environ Health 1988:14:189-96.

14. Schnall P, Pieper C, Shwartz JE, et al. The relationship between 'job strain', workplace diastolic blood pressure, and left ventricular mass index: results of a case-control study. JAMA 1990;263(14):1929-35.

15. Theorell T, Knox S, Svensson J, Waller D. Blood pressure variations during a working day at age 28: effects of different types of work and blood pressure level at age 18. J Human Stress 1985;11:36-41.

16. Chapman A, Mandryk JA, Frommer MS, Edye BV, Ferguson DA. Chronic perceived work stress and blood pressure among Australian government employees. Scand J Work Environ Health 1990;16:258-69.

17. Winkleby MA, Ragland DR, Syme SL. Self-reported stressors and hypertension: evidence of an inverse association. Am J Epidemiol 1988;127:124-34.

18. Theorell $\mathrm{T}$. Family history of hypertension - an individual trait interacting with spontaneously occurring job stressors. Scand J Work Environ Health 1990; 16(suppl 1):74-9.

19. Johnson JV, Stewart W, Fredlund P, Hall EM, Theorell T. Psychosocial job exposure matrix: an occupationally aggregated attribution system for work environment exposure characteristics. Stockholm: National Institute for Psychosocial Factors and Health, 1990. (Stress research reports; no 221.)

20. Theorell T, Hjemdahl P, Ericsson F, et al. Psychosocial and physiological factors in relation to blood pressure at rest - a study of Swedish men in their upper twenties. J Hyperten 1985;3:591-600.

Received for publication 26 April 1991 